\title{
Effect of Hyperventilation on Seizure Length During Electroconvulsive Therapy
}

\author{
Atul C. Pande, Julieanne Shea, Shashidhar Shettar, \\ Leon J. Grunhaus, and Roger F. Haskett
}

\section{Introduction}

Hyperventilation reportedly prolongs the seizures during eletroconvulsive therapy (ECT) (Bridenbaugh et al. 1972; Holmberg 1953; Holmberg et al. 1956; Weiner 1979; Chater and Simpson 1988). As these studies did not measure the $\mathrm{PCO}_{2}$ concentration it is unclear if prolongation of seizures was due to hyperoxygenation or hypocapnia. In a controlled study Bergsholm et al. (1984) demonstrated an increase in seizure length by hypocapnia but not by hyperoxygenation. The effect of different levels of hyperventilation-induced hypocapnia as measured by end-tidal $\mathrm{pCO}_{2}$ on seizure duration in ECT was evaluated in the present study to establish its practical utility in a clinical setting.

\section{Methods}

At the University of Michigan Hospital, fifteen depressed psychiatric inpatients who were free of psychotropic drugs were selected for ECT at

From the Depression Program (A.C.P., S.S., L.J.G., R.F.H.), the Electroconvulsive Therapy Program (A.C.P., L.J.G.), and the Department of Anesthesiology (J.S.), University of Michigan Medical Center, Ann Arbor, Michigan.

Presented as a paper at the Annual Meeting of the Society of Biological Psychiatry, Montreal, Canada, May 1988.

Address reprint requests to Dr. Atul C. Pande, 9D9702 UH, Box 0118, University of Michigan Hospital, 1500 E. Medical Center Drive, Ann Arbor, MI 48109-0118.

Received August 5, 1989; revised September 15, 1989. the University of Michigan Hospital were studied. None had had ECT in the preceding 6 months. Patients were assigned randomly to 1 of 3 groups based upon the end-tidal $\mathrm{pCO}_{2}(30,25$, or 20 $\mathrm{mmHg}$ ) achieved prior to their ECT. Right unilateral ECT was performed with a pulse wave MECTA SR-2 machine using fixed energy setting (approximately $90 \mathrm{~J}$ ) for each patient. Difficulty in reducing the $\mathrm{pCO}_{2}$ level below $25 \mathrm{~mm}$ with bag and mask ventilation alone necessitated endotracheal intubation in the lowest $\mathrm{pCO}_{2}$ group. One minute of rapid ventilation with pure oxygen was allowed from the induction of the anesthesia to achieve the designated $\mathrm{pCO}_{2}$ level that was maintained for $1 \mathrm{~min}$ before electrical stimulation. Ventilation was interrupted to administer the ECT and was resumed immediately afterward but with no attempt to maintain a low $\mathrm{pCO}_{2}$. Throughout the entire procedure, froin induction of anesthesia to return of spontaneous respiration, oxygen saturation was monitored by pulse oximetry and maintained at $100 \%$. Seizure length was monitored by the "cuff" method. Data were collected over the first 5 treatments for all patients.

Because the ventilatory procedure and the need for intubation in some patients were expected to require additional time, slightly higher than normal doses of anesthetic medications were used. Methohexital $1.5 \mathrm{mg} / \mathrm{kg}$ and succinylcholine $1.5 \mathrm{mg} / \mathrm{kg}$ were used for all patients to keep the drug effect constant in the three groups. 


\section{Results}

The subjects in the 3 groups were not significantly different for age $(57.3 \pm 14.2,62.4 \pm$ $15.9,63.4 \pm 15.5$ years for the $30 \mathrm{~mm}, 25$ $\mathrm{mm}$, and $20 \mathrm{~mm} \mathrm{pCO}_{2}$ groups respectively), although the gender distribution was uneven (Table 1). Comparison of seizure length showed that the lowest $\mathrm{pCO}_{2}$ group had the longest first seizure among the 3 groups. Within the series of 5 treatments in each group the first seizure was the longest as well. Seizure length declined precipitously by the second treatment, and subsequent treatments were indistinguishable for seizure length either among or within groups. As the data were not normally distributed, a nonparametric (Mann-Whitney) test was used.

\section{Discussion}

We found that hyperventilation had a transient effect on seizure length in the early phase of ECT. The first seizure length in the lowest $\mathrm{pCO}_{2}$ group was longer as compared to the other two groups, but this effect was not sustained for the remaining treatments. The first treatment in a course is known to be the longest (Fink 1979), and hyperventilation may have merely enhanced this effect. The large interindividual variability of seizure length in our sample suggests that intrinsic individual factors may influence seizure length. Because we did not cross patients over from one $\mathrm{PCO}_{2}$ level to another, we cannot comment on intraindividual responses to different levels of hypocapnia.

There are major methodological differences between this study and Bergsholm et al. (1984), thus making a comparison of results difficult. These authors intubated all patients, used etomidate as the anesthetic agent, and crossed patients from hyper- to normooxygenation and hypoto normocapnia in successive treatments so as to demonstrate differential effects of the two ventilatory states on EEG-monitored seizure length. On the contrary, we were looking for a clearly deinonstrable effect of varying levels of hypocapnia that could have clinical utilite. Hence, we adhered as closely as possible to our usual ECT procedure while varying the rate of ventilation to influence the end-tidal $\mathrm{pCO}_{2}$. Although we used a higher than usual methohexital dose, all groups were subject to the same dose, hence this factor alone may not explain our inability to find as robust an effect of hypocapnia on seizure length as did Bergsholm et al. (1984). "We suggest that hypocapnia as a strategy for prolonging seizure duration in routine clinical practice needs further study before it can be adopted into routine ECT practice. Moreover, as Bergsholm et al. (1984) have pointed out, the relationship of longer seizures to the clinical efficacy of ECT is in need of confirmation as well.

\section{Refurences}

Bergsholm P, Gran L, Bleie H (1984): Seizure duration in unilateral electroconvulsive therapy. The

Table 1. End Tidal $\mathrm{PCO}_{2}$ Levels and Seizure Duration in ECT

\begin{tabular}{|c|c|c|c|}
\hline & High $\mathrm{pCO}_{2}$ & $\begin{array}{l}\text { Medium } \\
\mathrm{CO}_{2}\end{array}$ & Low $\mathrm{pCO}_{2}$ \\
\hline & $(30 \mathrm{~mm})$ & $(25 \mathrm{~mm})$ & (20 mm) \\
\hline $\begin{array}{l}\text { Gender (M:F) } \\
\text { Seizure } \\
\quad(\text { sec, mean } \pm \text { sD) }\end{array}$ & $2: 3$ & $0: 5$ & $1: 4$ \\
\hline ECT \#1 & $72.0 \pm 13.1$ & $47.0 \pm 7.6$ & $105.8 \pm 41.7^{a}$ \\
\hline ECT \#2 & $66.3 \pm 33.2$ & $41.0 \pm 6.6$ & $54.6 \pm 19.1$ \\
\hline ECT \#3 & $48.3 \pm 14.9$ & $34.0 \pm 7.7$ & $58.0 \pm 22.8$ \\
\hline ECT \#4 & $54.0 \pm 32.5$ & $37.8 \pm 15.4$ & $52.3 \pm 27.9$ \\
\hline ECT \#5 & $44.7 \pm 17.9$ & $32.6 \pm 14.5$ & $34.8 \pm 3.6$ \\
\hline
\end{tabular}

${ }^{\circ} p<0.001$; all others NS (Mann-Whitney test). 
effect of hypocapnia induced by hyperventilation and the effect of ventilation with oxygen. Acta Psychiatr Scand 69:121-128.

Bridenbaugh RH, Drake FR, O'Regan TJ (1972): Multiple monitored electroconvulsive treatment in schizophrenia. Compr Psychiatry 13:9-17.

Chater SN, Simpson KH (1988): Effect of passive hyperventilation on seizure duration in patients undergoing electroconvulsive therapy. $\mathrm{Br} J \mathrm{An}$ aesth 60:70-73.

Cronholm B, Ottosson (1960): Experimental studies of the therapeutic action of electroconvulsive therapy in endogenous depression. Acta Psychiatr Scand (suppl) 145:69-101.
Fink M (1979): Convulsive Therapy: Theory and Practice. New York: Raven Press.

Holmberg G (1953): The influence of oxygen administration on electrically induced convulsions in man. Acta Psychiatr Neurol Scand 23:365-386.

Holmberg G, Hard G, Ramqvist N (1956): Experiments $i=1$ the prolongation of convulsions induced by electric shock treatment. Acta Psychiatr Neurol Scand 31:61-70.

Weiner RD (1979): The psychiatric use of electrically induced seizures. Am J Psychiatry 136:1507-1517. 